\title{
Vacancy-Wind Factors and Collective Correlation Factors in Nonstoichiometric B2 Intermetallic Compounds
}

\author{
K.L. Gosain ${ }^{1}$, D.K. Chaturvedi ${ }^{1, a}$, I.V. Belova ${ }^{2, b}$ and G.E. Murch ${ }^{2, c}$ \\ ${ }^{1}$ Department of Physics, Kurukshetra University, \\ Kurukshetra-136119, India \\ ${ }^{2}$ Diffusion in Solids Group \\ School of Engineering \\ The University of Newcastle \\ Callaghan, NSW 2308, Australia \\ a dhiraj chaturvedi@yahoo.co.in, ${ }^{b}$ Irina.Belova@newcastle.edu.au, \\ ${ }^{\mathrm{c}}$ Graeme.Murch@newcastle.edu.au
}

Keywords: Intermetallics, ordered alloys, tracer diffusion, chemical diffusion, correlation factors, six-jump-cycle, vacancy-wind

Abstract. The six-jump-cycle (6JC) diffusion mechanism is used to analyze the behavior of vacancy-wind factors and collective correlation factors in partially ordered B2 intermetallic compounds at stoichiometric and near- stoichiometric compositions. Expressions for the vacancywind factors are obtained in the framework of the four-frequency model where the two sublattices exist a priori. The phenomenological coefficients on the two sublattices that remain hitherto independent in 6JC mechanism are connected through a microscopic detailed balance condition. The present results for collective correlation factors when compared with our earlier calculation based on taking the harmonic mean of the sublattice correlation factors show much better agreement with Monte Carlo simulation results. The collective correlation factors and tracer correlation factors are used to calculate the vacancy-wind factors. Our results for vacancy-wind factors agree qualitatively with the simulation data when the frequency ratio $(\alpha)$ of structural and antistructural atoms jumps decreases up to the order of unity.

\section{Introduction}

The vacancy-wind effect [1-4] occurs when a collective diffusion process such as chemical diffusion (or ionic conductivity) causes a net flux of vacancies which is then distorted around a tracer atom causing non-random jumping of that tracer atom. The vacancy-wind effect is embodied in expressions for intrinsic diffusivities and interdiffusivities in the form of vacancy-wind factors [5-6].

The vacancy-wind factors can be expressed exactly in terms of the tracer and collective correlation factors as, see refs. [7-8]:

$$
\begin{aligned}
& r_{A}=\frac{\left(f_{A A}-C_{A} C_{B}^{-1} f_{A B}^{(A)}\right)}{f_{A}} \\
& r_{B}=\frac{\left(f_{B B}-C_{B} C_{A}^{-1} f_{A B}^{(B)}\right)}{f_{B}} \\
& S=\frac{C_{B} f_{A A}+C_{A} g f_{B B}-2 C_{A} g f_{A B}^{(A)}}{C_{A} g f_{B}+C_{B} f_{A}}
\end{aligned}
$$


where $r_{A}$ and $r_{B}$ are respectively the vacancy-wind factors for atoms of type $A$ and $B$ that occur in the intrinsic diffusivities and $\mathrm{S}$ is the vacancy-wind factor occurring in the interdiffusivity, $\mathrm{f}_{\mathrm{A}}$ and $\mathrm{f}_{\mathrm{B}}$ are the tracer correlation factors for $A$ and $B$ atoms respectively, $f_{A A}, f_{B B}, f_{A B}^{(A)}$ and $f_{A B}^{(B)}$ are the collective correlation factors and $\mathrm{C}_{\mathrm{A}(\mathrm{B})}$ is the site fraction of atoms $\mathrm{A}(\mathrm{B})$ and $\mathrm{g}$ is given by:

$$
g=\frac{\mathrm{C}_{\mathrm{A}}}{\mathrm{C}_{\mathrm{B}}}\left(\frac{\mathrm{L}_{\mathrm{BB}}^{(0)}}{\mathrm{L}_{\mathrm{AA}}^{(0)}}\right)
$$

where $\mathrm{L}^{(0)}$ are the uncorrelated parts of the phenomenological coefficients.

In the present paper, our aim is to investigate the experimentally accessible vacancy-wind factors and collective correlation factors [9-10] for partially ordered B2 intermetallic compound and at small deviations from the stoichiometric composition. Recently, expressions for tracer and collective correlation factors were obtained by us [11-12] for B2 intermetallic compound using the well known six-jump-cycle (6JC) mechanism of diffusion. The correlation factors were calculated by taking harmonic mean of the sublattice correlation factors, since the dynamics of the two sublattices remain independent of each other. In the present work we obtain the phenomenological coefficients for the system by connecting the expressions of sublattice phenomenological coefficients through the condition of detailed-balance. These collective correlation factors and the tracer correlation factors obtained earlier [11] are assembled to calculate the vacancy-wind factors.

\section{The Four-Frequency Model and the 6JC-frequency}

We consider an $\mathrm{AB}$ intermetallic compound where sublattice-1 constitutes the home sublattice of atoms of type B and sublattice-2 is the home sublattice of atoms of type A [13-14]. For two different kinds of vacancies, denoted as V1 and V2 on sublattices- 1 and 2 respectively, there are four nearest-neighbour atom-vacancy exchange frequencies. For example, $\mathrm{W}_{\mathrm{A} 1}$ denotes the jump frequency when an A atom on sublattice-1 exchanges its position with a vacancy V2 on sublattice-2. Similarly, we define $\mathrm{W}_{\mathrm{B} 1}, \mathrm{~W}_{\mathrm{A} 2}$ and $\mathrm{W}_{\mathrm{B} 2}$. In a nonstoichiometric compound, we consider the $6 \mathrm{JC}$ as a fundamental unit of diffusion for the cycle involving structural atoms, and the two-jump-cycle (2JC) as a fundamental unit for the cycle involving antistructural atom at the [110]type or [100]-type sites. The average jump frequency of a single isolated 6JC for a fully ordered configuration can be obtained as [11-12]:

$$
v_{\mathrm{B} 1} \equiv v_{\mathrm{A} 2}=\frac{\alpha^{3}\left(3+6 \alpha+4 \alpha^{2}\right)}{\left(288+1152 \alpha+2232 \alpha^{2}+2325 \alpha^{3}+1360 \alpha^{4}+364 \alpha^{5}+48 \alpha^{6}+4 \alpha^{7}\right)}
$$

where $\alpha$ is the ratio of jump frequencies of atoms going from the 'right' to the 'wrong' sublattice to that from the 'wrong' to 'right' sublattice:

$$
\alpha=\frac{\mathrm{W}_{\mathrm{B} 1}}{\mathrm{~W}_{\mathrm{B} 2}}=\frac{\mathrm{W}_{\mathrm{A} 2}}{\mathrm{~W}_{\mathrm{A} 1}}
$$

The average jump frequency of a single isolated 2JC for the antistructural atom can be written as [14]: 


$$
v_{\mathrm{A} 1} \equiv v_{\mathrm{B} 2}=\frac{2 \alpha}{(1+\alpha)}
$$

\section{Tracer correlation Factors}

In an earlier paper [11], using the 6JC mechanism we have obtained the tracer correlation factors when the frequencies of [110]-cycle, [100]-straight and [100]-bent cycles were taken to be equal. The tracer correlation factors for sublattice-1 are expressed as:

$$
\mathrm{f}_{\mathrm{T} 1}=1-\frac{v_{\mathrm{T} 1}}{3}\left[\frac{\left(2 \mathrm{~J}^{\prime}+\mathrm{J}\right)\left(\mathrm{b}_{\mathrm{T} 1}^{\prime}-2 \mathrm{~b}_{\mathrm{T} 1}\right)-\left(2 \mathrm{~J}^{\prime \prime}+\mathrm{J}^{\prime}\right)\left(\mathrm{a}_{\mathrm{T} 1}^{\prime}-2 \mathrm{a}_{\mathrm{T} 1}\right)}{\left(\mathrm{a}_{\mathrm{T} 1} \mathrm{~b}_{\mathrm{T} 1}^{\prime}-\mathrm{a}_{\mathrm{T} 1}^{\prime} \mathrm{b}_{\mathrm{T} 1}\right)}\right]
$$

where

$$
\begin{aligned}
& \mathrm{a}_{\mathrm{T} 1}=\left(1-\frac{\mathrm{J}}{2}\right) \mathrm{v}_{\mathrm{V} 1}+\mathrm{v}_{\mathrm{T} 1} \mathrm{~J} \quad ; \quad \mathrm{a}_{\mathrm{T} 1}^{\prime}=-\left(\mathrm{v}_{\mathrm{V} 1}-2 \mathrm{v}_{\mathrm{T} 1}\right) \mathrm{J}^{\prime} \\
& \mathrm{b}_{\mathrm{T} 1}=-\frac{1}{2}\left(\mathrm{v}_{\mathrm{V} 1}-2 \mathrm{v}_{\mathrm{T} 1}\right) \mathrm{J}^{\prime} \quad ; \quad \mathrm{b}_{\mathrm{T} 1}^{\prime}=\left(1-\mathrm{J}^{\prime \prime}\right) \mathrm{v}_{\mathrm{V} 1}+2 \mathrm{v}_{\mathrm{T} 1} \mathrm{~J}^{\prime \prime}
\end{aligned}
$$

and

$$
v_{\mathrm{V} 1}=\mathrm{C}_{\mathrm{A} 1} v_{\mathrm{A} 1}+\mathrm{C}_{\mathrm{B} 1} \mathrm{v}_{\mathrm{B} 1}
$$

where $v_{\mathrm{V} 1}$ is the vacancy escape frequency on sublattice- 1 . The $\mathrm{f}_{\mathrm{T} 2}$ can be obtained from the above equations by changing the subscript 1 as 2 . Here $v_{\mathrm{T} 1(2)}$ is $6 \mathrm{JC}$ frequency of the tracer, which is equal to that of $A$ and $B$ atoms on sublattice-1(2) when tracer atom $T=A, B$ respectively. The $J, J^{\prime}$ and $J^{\prime \prime}$ are the Brillouin-zone integrals whose values are given by $0.2416,0.0259$ and 0.1253 respectively. The tracer correlation factor $\mathrm{f}_{\mathrm{T}}$ is given by the harmonic mean of the sublattice tracer correlation factors $[11,14]$ as:

$$
\mathrm{f}_{\mathrm{T}}=2\left(\frac{1}{\mathrm{f}_{\mathrm{T} 1}}+\frac{1}{\mathrm{f}_{\mathrm{T} 2}}\right)^{-1}
$$

\section{Phenomenological Coefficients and Collective Correlation Factors}

The phenomenological transport coefficients $\mathrm{L}_{\mathrm{ij}}(\mathrm{i}, \mathrm{j}=\mathrm{A}, \mathrm{B})$ for an intermetallic compound can be expressed as [15]:

$$
\mathrm{L}_{\mathrm{ij}}=\mathrm{L}_{\mathrm{ilj1} 1}+\mathrm{L}_{\mathrm{i} 2 \mathrm{j} 2}+2 \mathrm{~L}_{\mathrm{i} 1 \mathrm{j} 2}
$$


where $\mathrm{L}_{\mathrm{i} 1 \mathrm{j} 1}$ and $\mathrm{L}_{\mathrm{i} 2 \mathrm{j} 2}$ are respectively the phenomenological coefficients for sublattices-1 and 2 respectively. The Onsager reciprocity condition relates the cross-coefficients $\mathrm{L}_{\mathrm{ilj2}}=\mathrm{L}_{\mathrm{i} 2 \mathrm{j} 1}$. When diffusion is governed by the 6JC mechanism [16-17], the dynamics on the two sublattices is independent of each other since vacancy on a particular sublattice has no means of switching over to the other sublattice. Consequently, the cross-coefficients vanish and we have that:

$$
\mathrm{L}_{\mathrm{ij}}=\mathrm{L}_{\mathrm{i} 1 \mathrm{j} 1}+\mathrm{L}_{\mathrm{i} 2 \mathrm{j} 2}
$$

For the evaluation of the $\mathrm{L}_{\mathrm{ij}}$, we follow the general linear response theory of Allnatt and Lidiard [18] and divide it into the uncorrelated and correlated parts. The uncorrelated and correlated parts of the phenomenological coefficients for the sublattice, say sublattice-1, can be obtained as; see [12]:

$$
\begin{gathered}
\mathrm{L}_{\mathrm{i} 1 \mathrm{j} 1}^{(0)}=\delta_{\mathrm{ij}}\left(\frac{6 \mathrm{Na}^{2}}{\mathrm{k}_{\mathrm{B}}^{\mathrm{T}}}\right) \mathrm{C}_{\mathrm{V} 1} \mathrm{C}_{\mathrm{i} 1} v_{\mathrm{i} 1} \\
\mathrm{~L}_{\mathrm{i} 1 \mathrm{j} 1}^{(1)}=\left(1-2 \delta_{\mathrm{ij}}\right)\left(\frac{2 \mathrm{Na}^{2}}{\mathrm{k}_{\mathrm{B}} \mathrm{T}}\right) v_{\mathrm{i} 1} v_{\mathrm{j} 1} \mathrm{C}_{\mathrm{v} 1} \mathrm{C}_{\mathrm{i} 1}\left(1-\mathrm{C}_{\mathrm{i} 1}\right)\left[\frac{\left(2 \mathrm{~J}^{\prime}+\mathrm{J}\right)\left(\mathrm{b}_{1}^{\prime}-2 \mathrm{~b}_{1}\right)-\left(2 \mathrm{~J}^{\prime \prime}+\mathrm{J}^{\prime}\right)\left(\mathrm{a}_{1}^{\prime}-2 \mathrm{a}_{1}\right)}{\left(\mathrm{a}_{1} \mathrm{~b}_{1}^{\prime}-\mathrm{a}_{1}^{\prime} \mathrm{b}_{1}\right)}\right]
\end{gathered}
$$

where

$$
\begin{aligned}
& a_{1}=\left(1-\frac{J}{2}\right) v_{v 1}+v_{1} J \quad ; \quad a_{1}^{\prime}=-\left(v_{v 1}-2 v_{1}\right) J^{\prime} \\
& \mathrm{b}_{1}=-\frac{1}{2}\left(v_{\mathrm{V} 1}-2 v_{1}\right) \mathrm{J}^{\prime} \quad ; \quad \mathrm{b}_{1}^{\prime}=\left(1-\mathrm{J}^{\prime \prime}\right) v_{\mathrm{V} 1}+2 v_{1} \mathrm{~J}^{\prime \prime}
\end{aligned}
$$

and

$$
v_{1}=\mathrm{C}_{\mathrm{A} 1} v_{\mathrm{B} 1}+\mathrm{C}_{\mathrm{B} 1} v_{\mathrm{A} 1}
$$



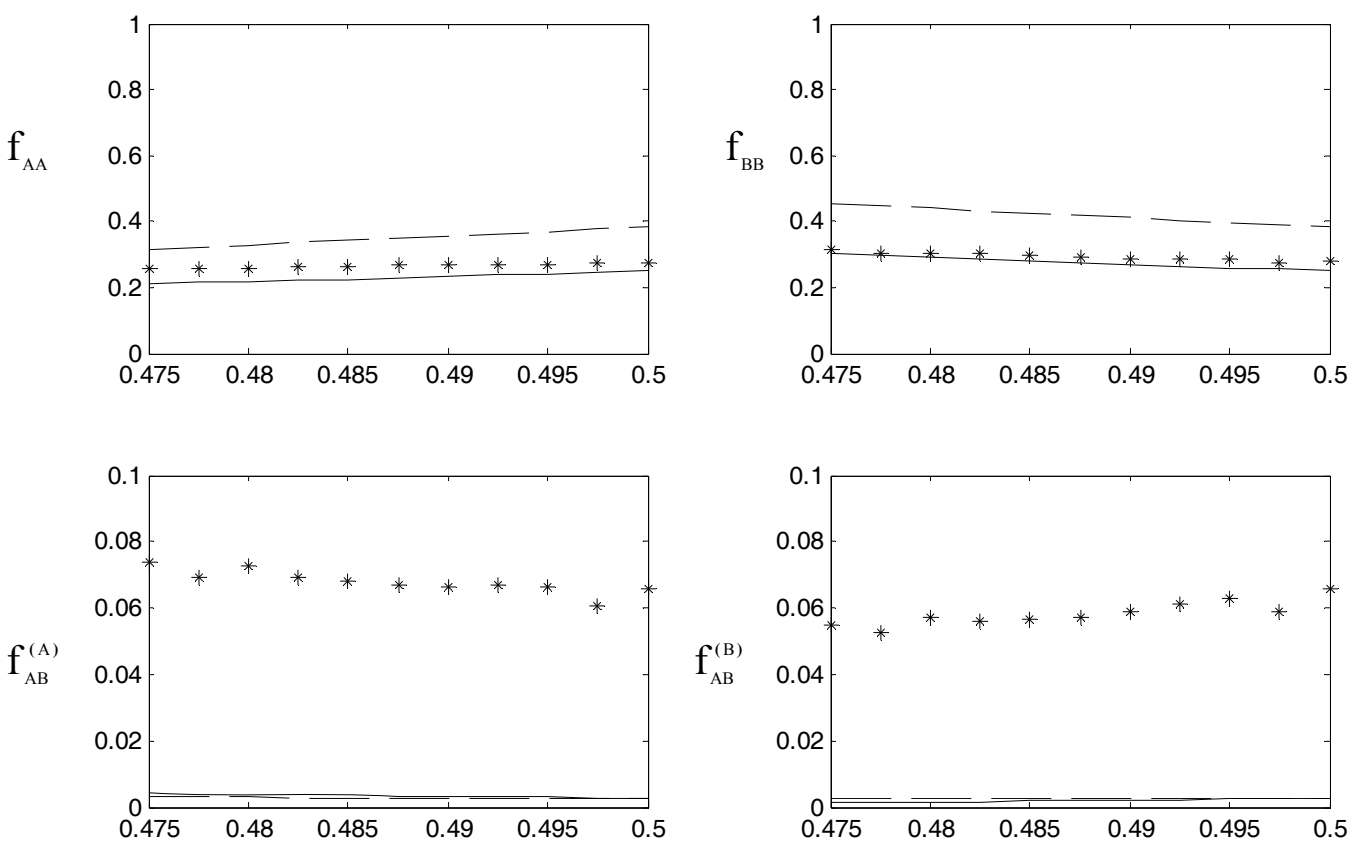

Figure 1. Collective correlation factors $\mathrm{f}_{\mathrm{AA}}, \mathrm{f}_{\mathrm{BB}}, \mathrm{f}_{\mathrm{AB}}^{(\mathrm{A})}, \mathrm{f}_{\mathrm{AB}}^{(\mathrm{B})}$ as a function of $\mathrm{C}_{\mathrm{A}}$ for $\alpha=0.1:(-)$ Calculated values, $(* * *)$ Simulation results, (------) harmonic mean method.
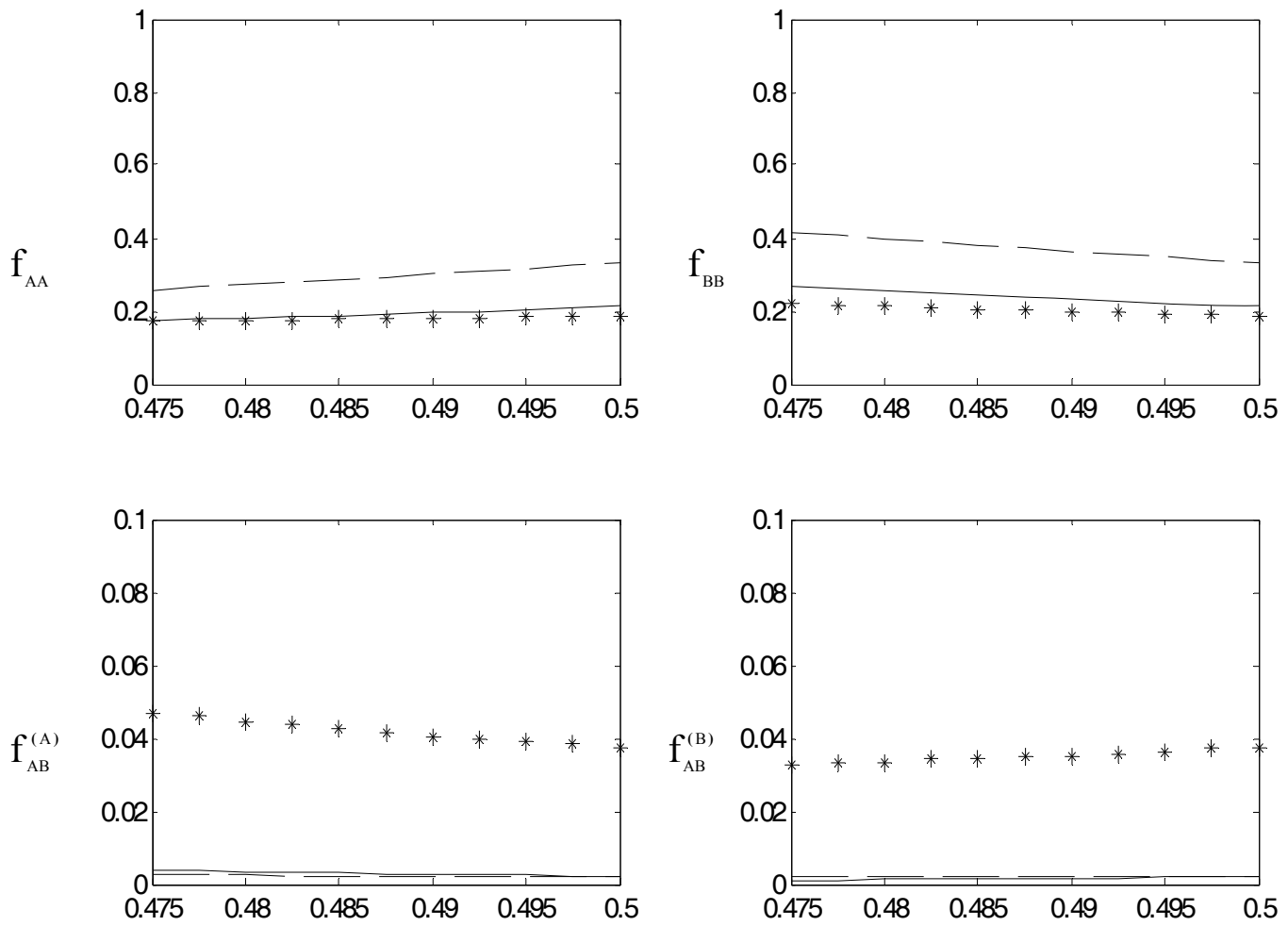

Figure 2. Collective correlation factors $\mathrm{f}_{\mathrm{AA}}, \mathrm{f}_{\mathrm{BB}}, \mathrm{f}_{\mathrm{AB}}^{(\mathrm{A})}, \mathrm{f}_{\mathrm{AB}}^{(\mathrm{B})}$ as a function of $\mathrm{C}_{\mathrm{A}}$ for $\alpha=0.08$ : Calculated values, $(* * *)$ Simulation results, (-----) harmonic mean method. 

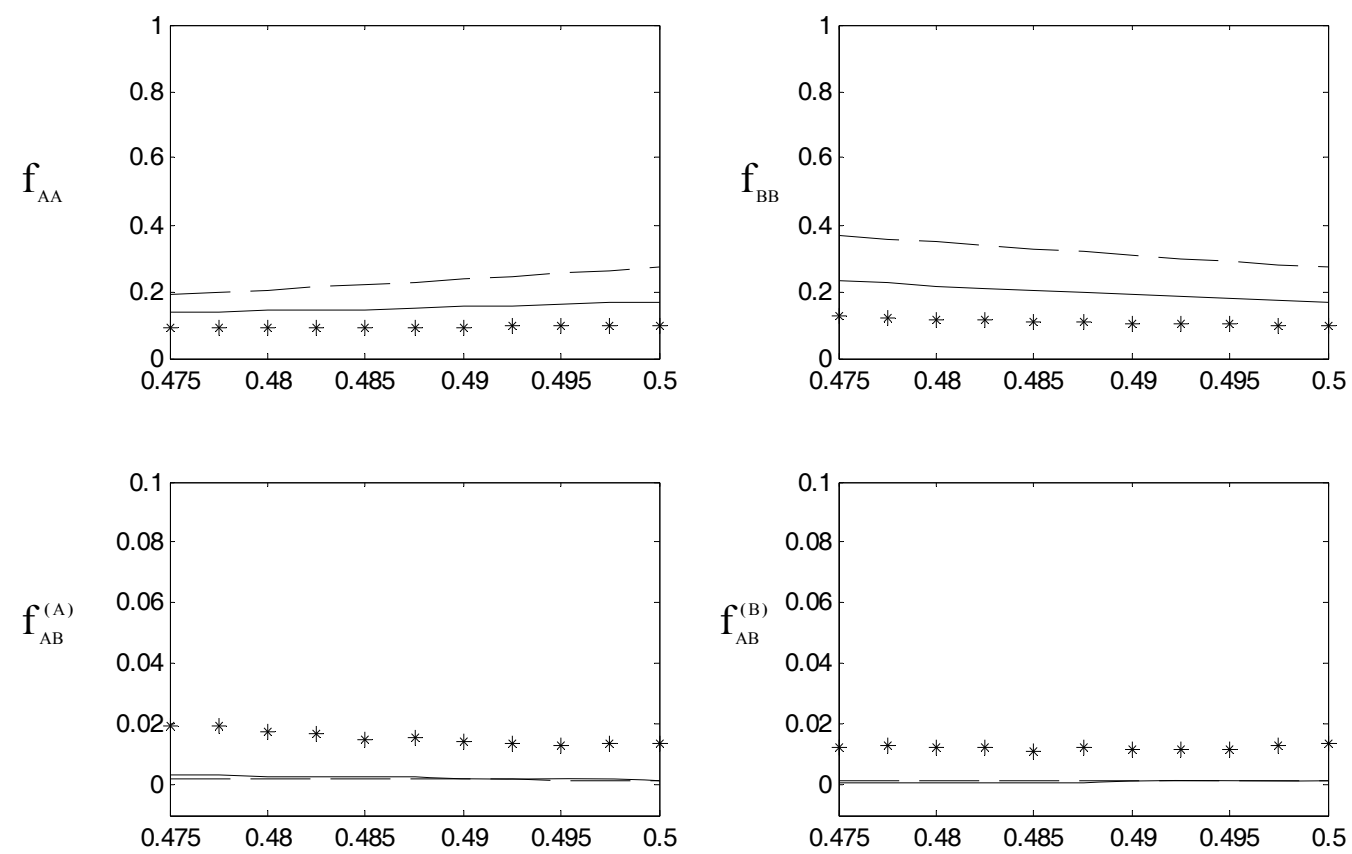

Figure 3. Collective correlation factors $\mathrm{f}_{\mathrm{AA}}, \mathrm{f}_{\mathrm{BB}}, \mathrm{f}_{\mathrm{AB}}^{(\mathrm{A})}, \mathrm{f}_{\mathrm{AB}}^{(\mathrm{B})}$ as a function of $\mathrm{C}_{\mathrm{A}}$ for $\alpha=0.06$ : Calculated values, $(* * *)$ Simulation results, (----) harmonic mean method.
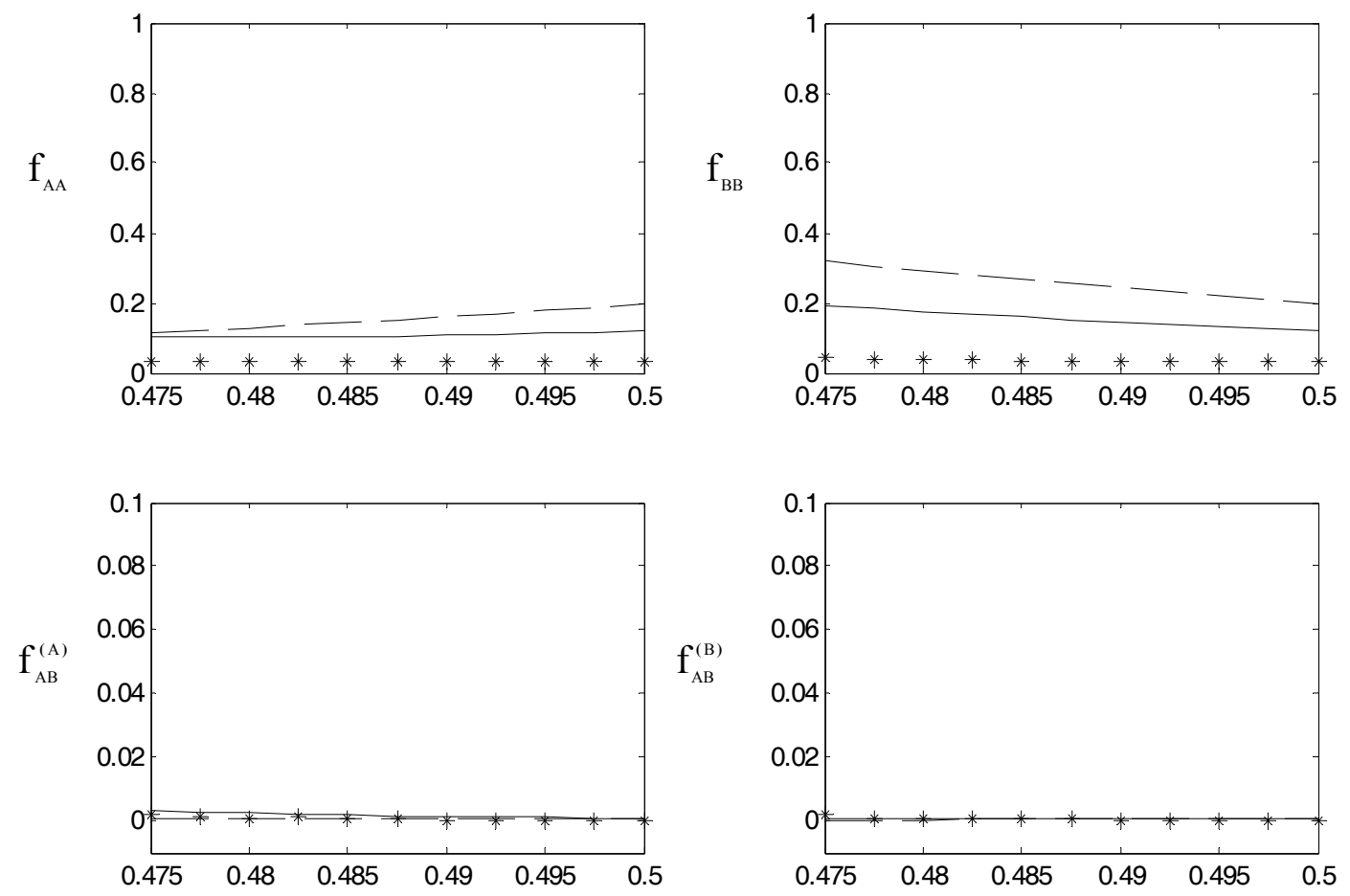

Figure 4. Collective correlation factors $\mathrm{f}_{\mathrm{AA}}, \mathrm{f}_{\mathrm{BB}}, \mathrm{f}_{\mathrm{AB}}^{(\mathrm{A})}, \mathrm{f}_{\mathrm{AB}}^{(\mathrm{B})}$ as a function of $\mathrm{C}_{\mathrm{A}}$ for $\alpha=0.04$ : ( $(-)$ Calculated values, $(* * *)$ Simulation results, (-----)harmonic mean method. 

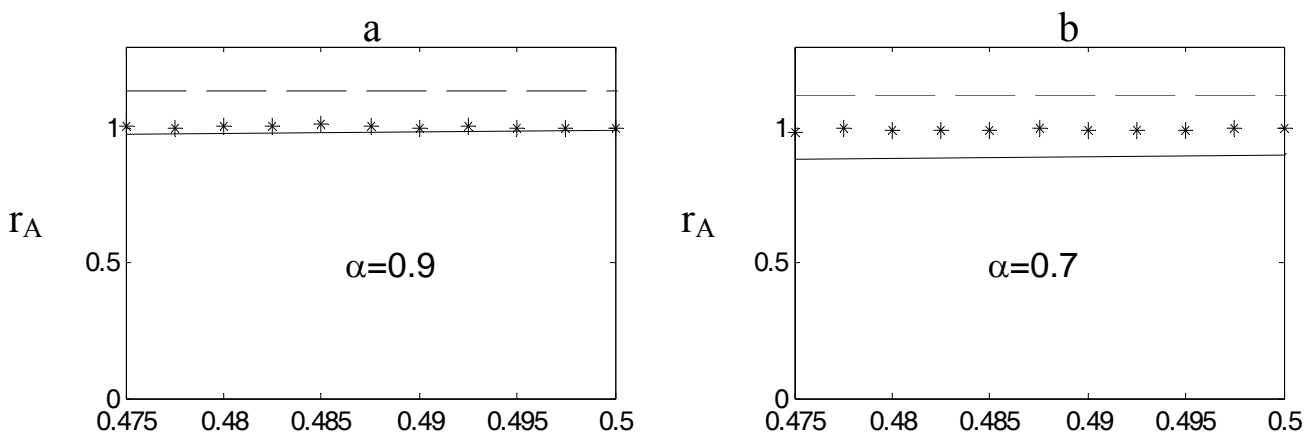

c

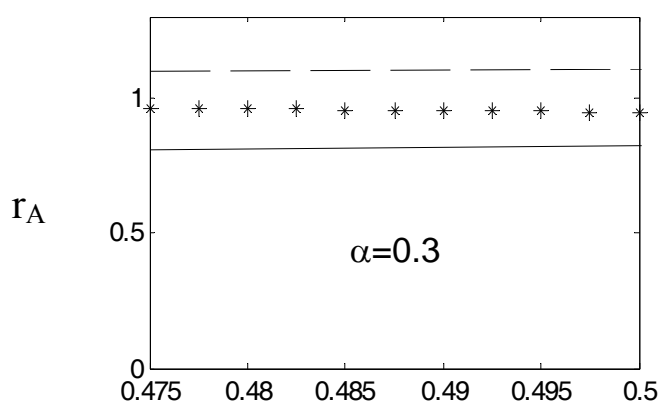

d

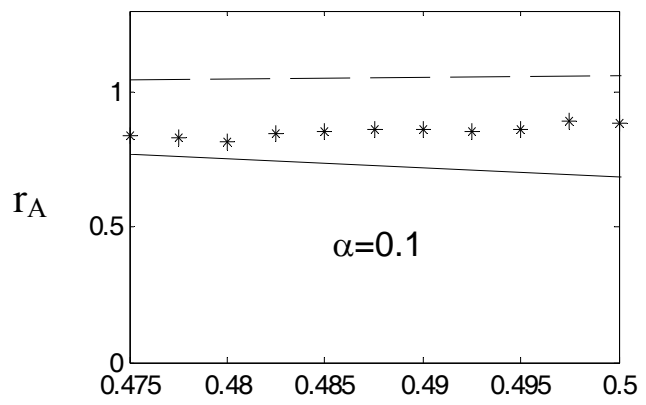

Figure 5. Vacancy-wind factor $\mathrm{r}_{\mathrm{A}}$ as a function $\mathrm{C}_{\mathrm{A}}$ for (a) $\alpha=0.9$, (b) $\alpha=0.7$, (c ) $\alpha=0.5$ and (d) $\alpha=0.1$ Monte Carlo simulation -*, solid lines -present method, dashed line -harmonic mean method.

a
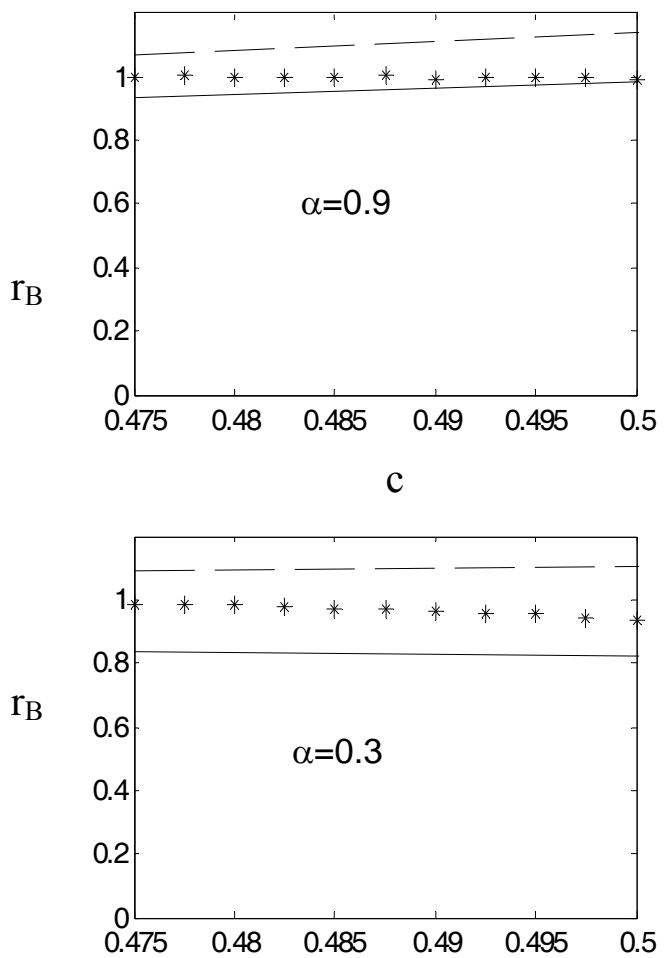

$\mathrm{b}$
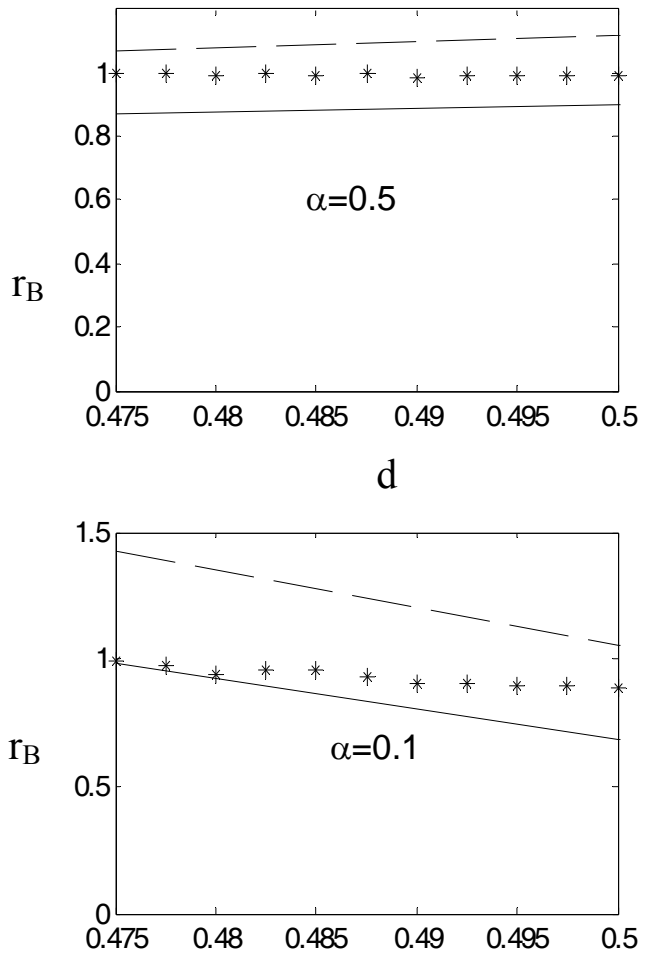

Figure 6. Vacancy-wind factor $\mathrm{r}_{\mathrm{B}}$ as a function $\mathrm{C}_{\mathrm{A}}$ for (a) $\alpha=0.9$, (b) $\alpha=0.7$, (c ) $\alpha=0.5$ and (d) $\alpha=0.1$ Monte Carlo simulation -*, solid lines -present method, dashed line -harmonic mean method. 
a
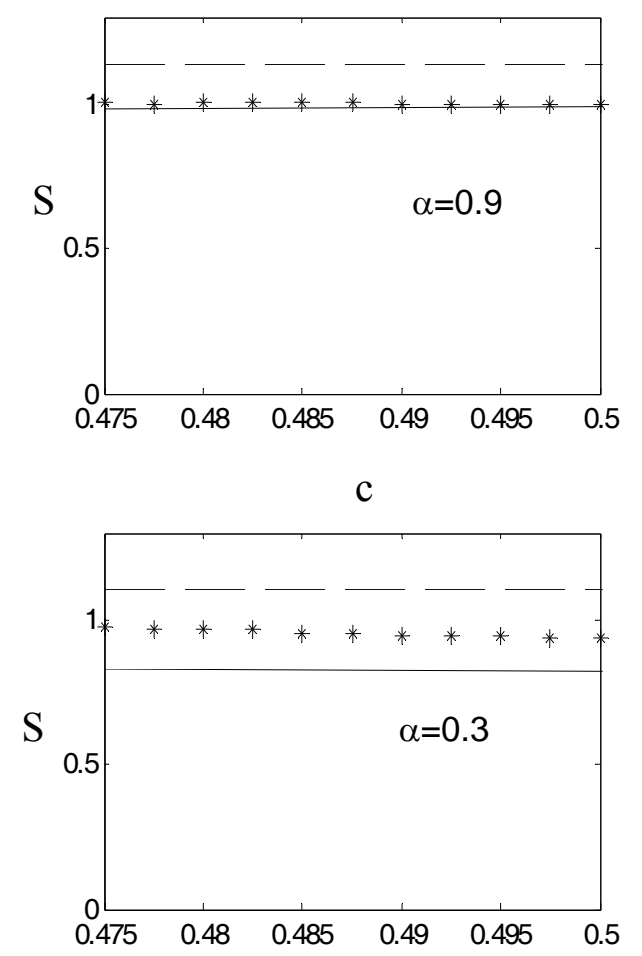

b
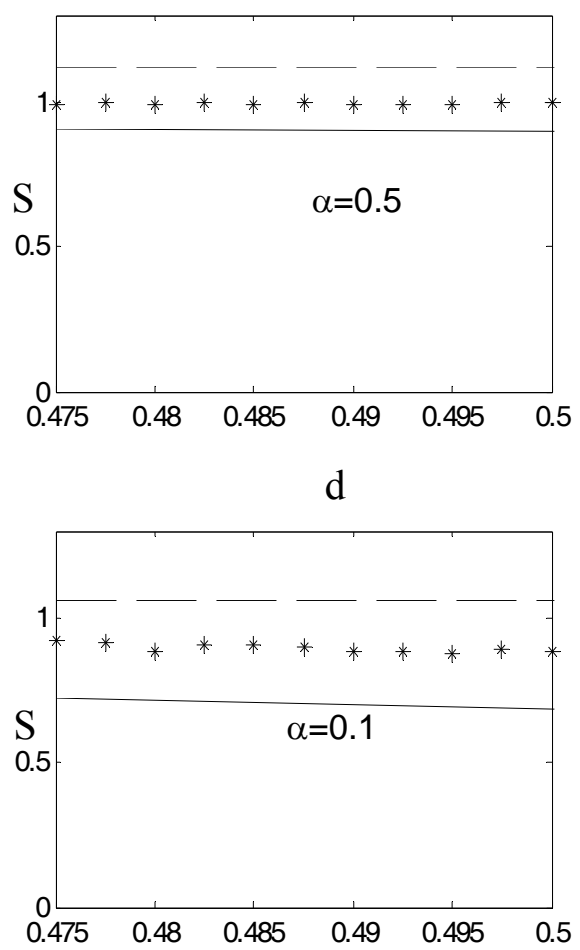

Figure 7. Vacancy-wind factor $\mathrm{S}$ as a function $\mathrm{C}_{\mathrm{A}}$ for (a) $\alpha=0.9$, (b) $\alpha=0.7$, (c ) $\alpha=0.5$ and (d) $\alpha=0.1$ Monte Carlo simulation -*, solid lines - present method, dashed line - harmonic mean method.

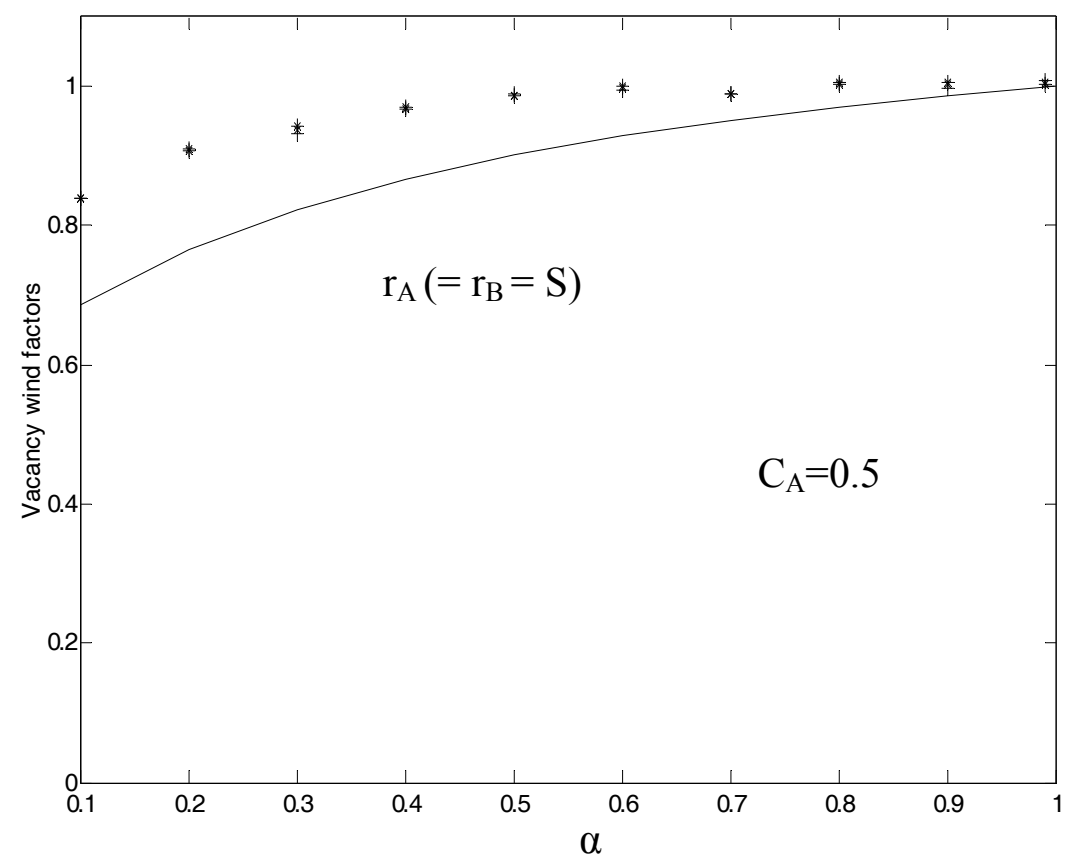

Figure 8. Vacancy-wind factors factors $\mathrm{r}_{\mathrm{A}}, \mathrm{r}_{\mathrm{B}}$ and $\mathrm{S}$ as a function of $\alpha$ at the stoichiometric composition $\left(C_{A}=0.5\right)$ for the $B 2$ intermetallic compound. Solid line: present calculations for $r_{A}\left(=r_{B}=S\right)$. Symbols: Monte Carlo simulation, * - for $\mathrm{r}_{\mathrm{A}} ; \mathrm{x}$-for $\mathrm{r}_{\mathrm{B}} ;+$ - for $\mathrm{S}$. 
a

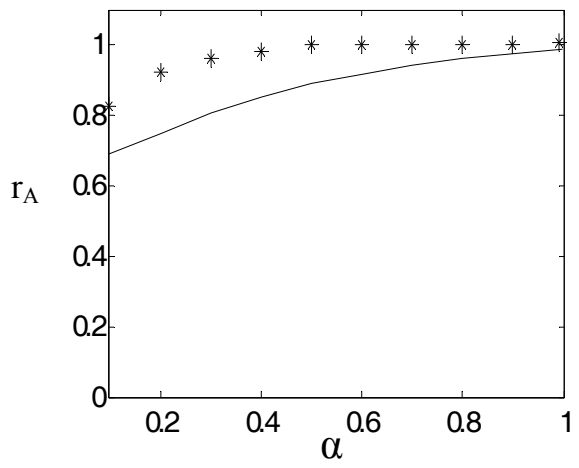

$\mathrm{c}$

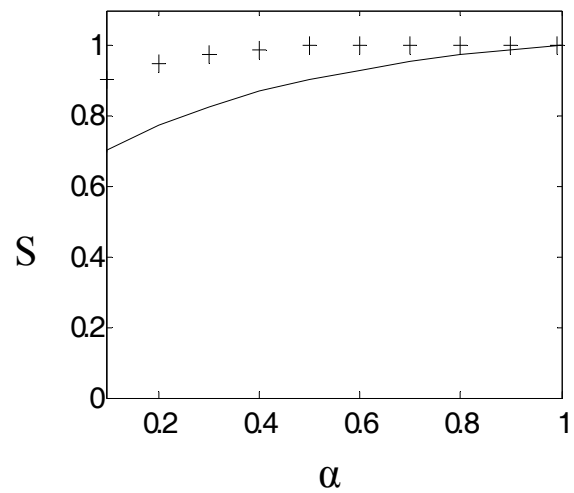

$\mathrm{b}$

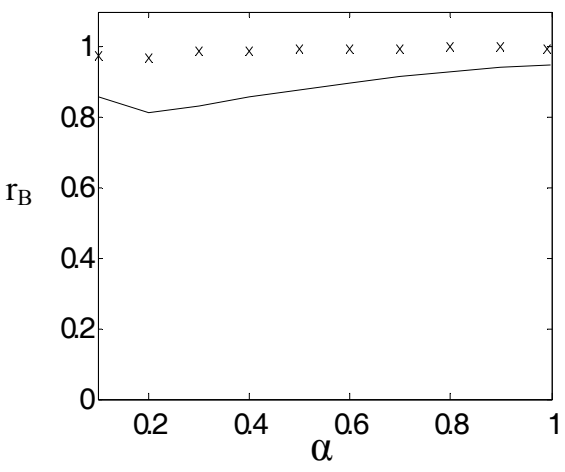

Figure 9. Vacancy-wind factors $\mathrm{r}_{\mathrm{A}}, \mathrm{r}_{\mathrm{B}}$ and $\mathrm{S}$ as a function of $\alpha$ at the non-stoichiometric composition $\left(\mathrm{C}_{\mathrm{A}}=0.48\right)$ for the B2 intermetallic compound. Solid line: present calculations. Symbols: Monte Carlo simulation, * - for $\mathrm{r}_{\mathrm{A}} ; \mathrm{x}$-for $\mathrm{r}_{\mathrm{B}}$; +- for $\mathrm{S}$.

The expressions for the sublattice- 2 can be obtained from above by interchanging the subscripts 1 and 2. The phenomenological coefficients $\mathrm{L}_{\mathrm{ij}}$ are obtained from Eq. 12 by combining the results of the two sublattices using the detailed balance condition given as:

$$
\frac{\mathrm{C}_{\mathrm{V} 2}}{\mathrm{C}_{\mathrm{V} 1}}=\left(\frac{\mathrm{C}_{\mathrm{A} 2} \mathrm{C}_{\mathrm{B} 2} \mathrm{~W}_{\mathrm{A} 2} \mathrm{~W}_{\mathrm{B} 2}}{\mathrm{C}_{\mathrm{A} 1} \mathrm{C}_{\mathrm{B} 1} \mathrm{~W}_{\mathrm{A} 1} \mathrm{~W}_{\mathrm{B} 1}}\right)^{1 / 2}
$$

The collective correlation factors are then given by:

$$
\mathrm{f}_{\mathrm{ij}}^{(\mathrm{j})}=\delta_{\mathrm{ij}}+\frac{\mathrm{L}_{\mathrm{ij}}^{(1)}}{\mathrm{L}_{\mathrm{jj}}^{(0)}}
$$

The superscript $\mathrm{j}$ is omitted when $\mathrm{i}=\mathrm{j}$.

\section{Results and Discussion}

In order to verify the above relations for collective correlation factors, we represent in Figs. 1-4 the $\mathrm{f}_{\mathrm{ij}}$ as a function of equilibrium composition of $\mathrm{A}$ atoms $\left(\mathrm{C}_{\mathrm{A}}\right)$ at fixed values of jump frequencies ratio $\alpha=0.1,0.08,0.06,0.04$. The results for collective correlation factors are compared with the results of Monte Carlo simulation based on single vacancy jumps. Results are also compared with our earlier calculation based on the harmonic mean of the sublattice correlation factors. The agreement of the present results with the Monte Carlo simulation data is quite good for diagonal collective correlation factors $\left(f_{A A}\right.$ and $\left.f_{B B}\right)$ as compared to off-diagonal ones $\left(f_{A B}^{(A)}=f_{B A}^{(A)}\right.$ and 
$\left.\mathrm{f}_{\mathrm{AB}}^{(\mathrm{B})}=\mathrm{f}_{\mathrm{BA}}^{(\mathrm{B})}\right)$ at $\alpha=0.1$ as shown in Fig. 1. The cross correlation factors are much smaller and are of the order of $10^{-2}$. However, all the four correlation factors agree closely with the simulation results at $\alpha=0.04$ (See Fig. 4).

The results for vacancy-wind factors $r_{A}, r_{B}$ and $S$ are shown in Figs. 5, 6 and 7 respectively as a function of $\mathrm{C}_{\mathrm{A}}$ at fixed values of jump frequencies ratio $\alpha=0.9,0.5,0.3,0.1$. The present results for $r_{A}, r_{B}$ and $S$ are in much better agreement with the simulated values as compared to that obtained using harmonic mean method. Fig. 8 shows the variation of the vacancy-wind factors $r_{A}$ $\left(=r_{B}=S\right)$ with $\alpha$ at stoichiometry for the symmetric case where asymmetry parameter is unity [19]. At $\alpha=1$, the distinction between the two sublattices is lost and A behaves exactly the same as B (apart from identity). Under such conditions $\mathrm{D}_{A}^{\mathrm{I}}=\mathrm{D}_{B}^{\mathrm{I}}$ and $\mathrm{r}_{\mathrm{A}}=\mathrm{r}_{\mathrm{B}}=1$. This is verified in the Fig. 8 . Physically, $\mathrm{D}_{\mathrm{A}}^{\mathrm{I}}=\mathrm{D}_{\mathrm{B}}^{\mathrm{I}}$ means that there would be no marker shift in the interdiffusion experiment and consequently no net vacancy flux. Without a vacancy flux, there can be no vacancy-wind effect and both $r_{A}$ and $r_{B}$ are trivially equal to unity. In Fig. 9 we have shown $r_{A}, r_{B}$ and $S$ as a function of $\alpha$ at small deviation from stoichiometry $\left(\mathrm{C}_{\mathrm{A}}=0.48\right)$. The results are qualitatively similar to the simulation data, except that the deviation from the simulation data increases as $\alpha$ decreases.

\section{Acknowledgments}

One of us (KLG) is grateful to the University Grants Commission, New Delhi for the award of a Teacher Fellowship and wishes to thank the Principal, Dyal Singh College, Karnal and Commissioner, Higher Education, Haryana for sanctioning study leave. We wish to thank the Australian Research Council for its support of this research.

\section{References}

[1] J.R. Manning, Diffusion Kinetics for Atoms in Crystals (Van Nostrand, Princeton NJ 1968).

[2] G. E. Murch and Z. Qin, Defect and Diffusion Forum, 109-110 (1994), p.1.

[3] G. E. Murch, in Diffusion in Crystalline Solids, edited by G. E. Murch and A. S. Nowick, Academic Press, Orlando Florida (1984), p.379.

[4] G. E. Murch, in Phase Transformations in Solids, Material Science and Technology, Vol. 5, Chapter 2, edited by P. Haasen, VCH, Weinheim (1991), p.75.

[5] I.V. Belova and G.E. Murch, Defect and Diffusion Forum, 213-215 (2003), p.95.

[6] I.V. Belova and G.E. Murch, Defect and Diffusion Forum, 237-240 (2005), p.291.

[7] I.V. Belova and G.E. Murch, Phil. Mag. A, 81 (2001), p.83.

[8] I.V. Belova and G.E. Murch, Defect and Diffusion Forum, 179-180 (2000), p.1.

[9] I.V. Belova and G.E. Murch, Phil. Mag. A, 82 (2002), p. 285.

[10] I.V. Belova and G.E. Murch, J. Phys. Condensed Matter, 14 (2002), p. 9563.

[11] K. L. Gosain, D. K. Chaturvedi, I.V. Belova and G.E. Murch, Defect and Diffusion Forum, 247-248 (2005), p. 9.

[12] K. L. Gosain, D. K. Chaturvedi, I.V. Belova and G.E. Murch, Defect and Diffusion Forum, in press.

[13] I.V. Belova and G.E. Murch, Phil. Mag. A, 73 (1996), p117.

[14] H. Bakker, Phil. Mag. A, 40 (1979), p.525.

[15] I.V. Belova and G.E. Murch, Defect and Diffusion Forum, 194-199 (2001), p.547.

[16] M. Arita, M. Koiwa and S. Ishioka, Acta Metall., 37 (1989), p.1363.

[17] R. Drautz and M. Fahnle, Acta Mater, 47 (1999),p.2437.

[18] A.R. Allnatt and A.B. Lidiard, Atomic Transport in Solids (Cambridge University Press, London 1993).

[19] G.E. Murch and I.V. Belova, Defect and Diffusion Forum, 194-199 (2001), p.533. 
Defects and Diffusion Ceramics Abstracts

doi:10.4028/3-908451-28-0

Vacancy-Wind Factors and Collective Correlation Factors in Nonstoichiometric B2

Intermetallic Compounds

doi:10.4028/3-908451-28-0.69 